\title{
The Architectural and Cultural Heritage of Sabah - The Rungus Longhouse
}

\author{
Azizi Bahauddin ${ }^{1}$ \\ ${ }^{1}$ School of Housing, Building and Planning, Universiti Sains Malaysia, Minden, 11800 Penang, \\ Malaysia
}

\begin{abstract}
This paper dwells into heritage tourism that is related to the architectural and cultural heritage of the Rungus people of Sabah, Malaysian Borneo. It investigates the cultural influence on the architecture of the longhouse. The Rungus tribal group can be found in the northeast corner of Sabah, farming the land mostly on agricultural products in small scale plantations. Their longhouses, facing extinction, are dual-purpose dwellings, constructed entirely of traditional materials utilising small split timbers lashed with rattan for the frame, palm fronds for the thatched roof, split bamboo for the floor and tree bark of hewn wood for the compartment walls. Each family has its own separate quarters off a common hall for socialising and community work and village life is usually based on the cultural traditions. Strongly related to the spirit of the place, the 'rice spirit', in particular, figures prominently in the Rungus people's beliefs and practices in controlling the spirits and the people's daily life and often governed by the words of the bobohizans, the high priestess. The objectives gear towards analysing the architectural values and investigating cultural understanding associated with the longhouses. Most importantly, the issue of how the Rungus people relate to the environment is studied through the tangible and intangible cultural aspects of the people. The research utilises the observation technique, interviews with the residents, visual data collection and measured drawings of five longhouses as the processes to document data. The paper instigates an investigation into the conformity of the Rungus people of their place in the environment to perpetuate their lifestyle blessed with a unique heritage found in their architecture and culture, in a land where nature reigns. It is a heritage that worth a second look in the tourism industry of Sabah.
\end{abstract}

\section{Introduction}

This paper looks into the perspective of cultural heritage as an attraction to a destination. One aspect of tourism that can be capitalised on is from the heritage point of view. The industry stresses the importance of local culture relating to the tourists' experience. It can be achieved with the blend of culture and tourism and coined as the commodification of culture. In order to use tourism as a selling point in developing locality, the community must rely on culture and its cultural symbols as a selling point to attract tourists; for instance, folk tales, arts, traditions, heritage, and even local geography can be tourist draws [1]. Heritage architecture can provide a substantial impact on tourism activities by providing tourists to a destination with examples of local architecture. It further provides a long 
lasting connection with a tourist destination, a symbolic reference to a destination. Similarly, the cultural heritage can be highlighted for the Rungus people of Sabah.

The indigenous people of Sabah and Sarawak are synonymous with their longhouse architecture. Unfortunately, the Rungus people of Kudat in the Bengkoka Peninsula, the sub-group of the KadazanDusun [2], with their longhouse design are receiving lack of attention. In theory, the longhouses have long existed as a mode of rural settlement, particularly among the indigenous peoples of Sabah and Sarawak [3]. However, Malaysians in general have a vague conception of Rungus culture as well as the architectural language of this longhouse as a housing pattern, with clear-cut boundaries of public and private spaces for the domestic families dwelling in these longhouses. This is due to the lack of research being done about this community and its architecture. To aggravate further the situation of lack of information, the Rungus community has been relocated to their new settlements away from their ancestral land [4]. The original landscape of the Rungus people in Kudat includes puru, patches of forest approximately one hectare in size and inhabited by rogon (spirits) [5]. But these areas are reducing in size. The problem indicates that the people are also losing their architectural heritage through the relocation of their settlements.

The Rungus people of Kudat are a sub-group of Kadazan-Dusun, Sabah's major indigenous people on the island of Malaysian Borneo (figure $1 \&$ figure 2). Troubled by the relocation of settlements, these people are losing their strong foothold in their traditional land tenure where each village held rights as a corporate entity over its territory. The villages had clear boundaries and only members of it could harvest their cultivated open lands in this territory annually. Once the last crops were removed, the areas are given back to the control of the village and could be used again by anyone in the village in a system called 'circulating usufruct' (the right to enjoy benefits) [4]. However, the right is slowly stripped away hence the loss of their communal architectural heritage with less than ten houses remaining.

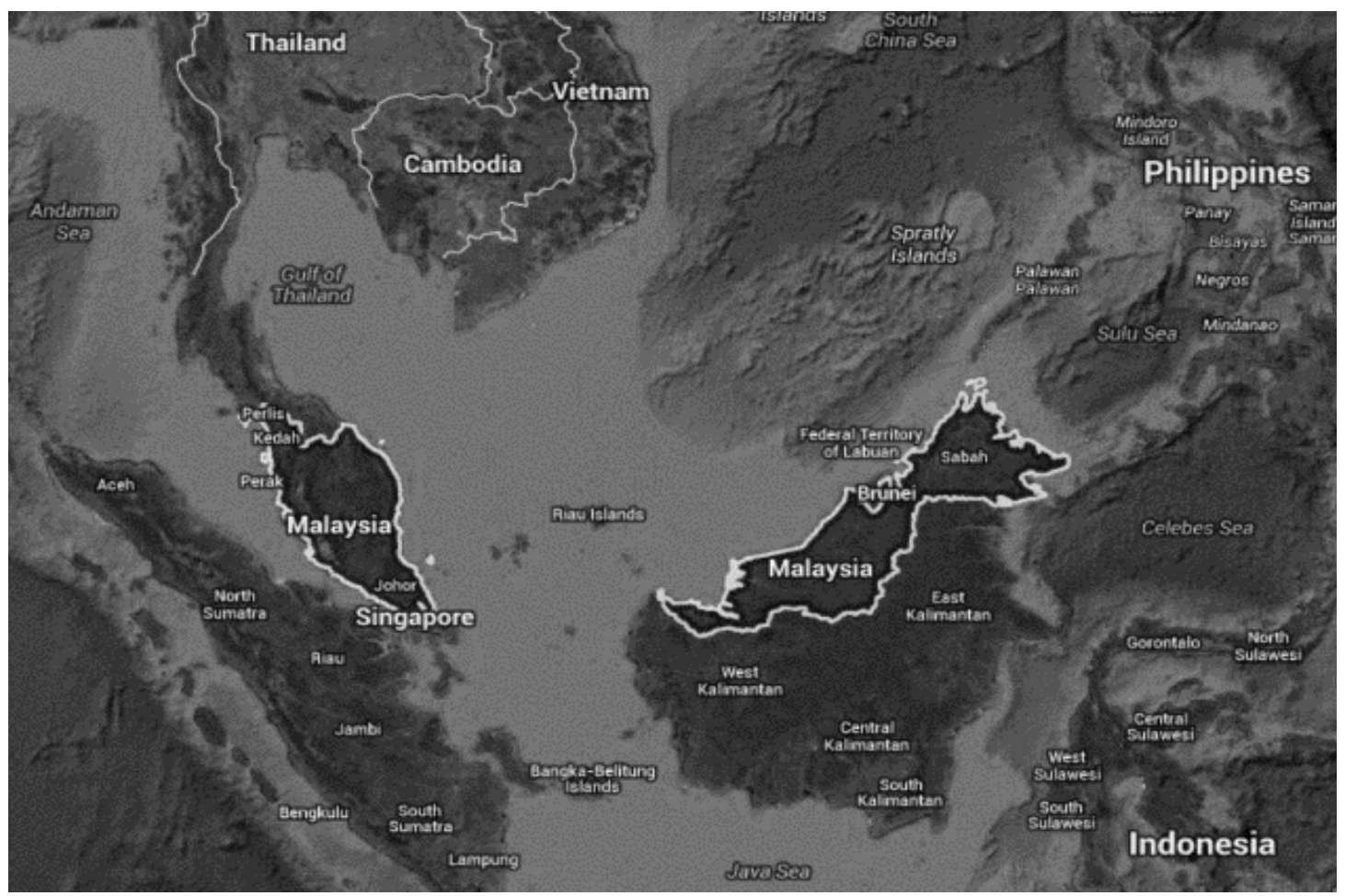

Figure 1. Map of Sabah on the Malaysian Borneo Island 


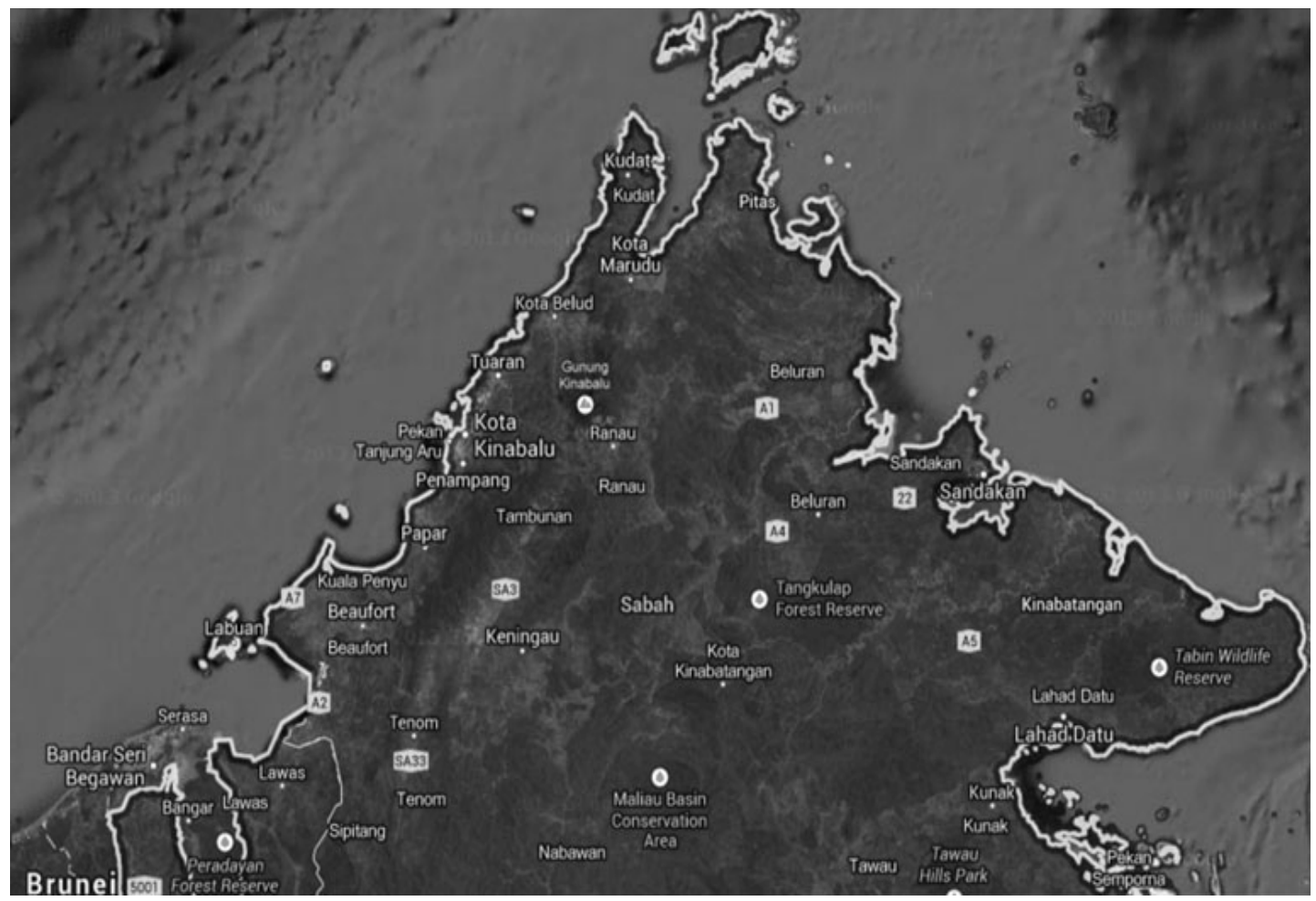

Figure 2. Map of Sabah

Culturally, the house is the embodiment of the community reflecting all communal rules and customs. The research aims:

a. To investigate the architectural and cultural aspects of a communal dwelling of the Rungus longhouse

b. To examine the cultural influences that dictate the communal space planning of the Rungus longhouse and its environment

c. To establish an architectural language between the philosophy of the detail embellishments and the Rungus longhouse for design understanding

There is no current exploratory research being done in understanding the Rungus longhouse in relation to its communal dwelling. This can be done by studying the traditional philosophy of the Rungus people. This research embarks into an unchartered territory that can be perceived as a new angle of studying a longhouse design setting in relation to communal dwelling. This investigation delves into the meaning of Rungus culture in order to understand the architecture of the longhouse by employing a few steps as research method.

\section{Cultural heritage tourism}

In dealing with heritage tourism, one has to look at the motivations for tourist to visit sites. In the case of the Rungus people, the Kudat area is considered a place with natural charms. According to Prentice [6], in research dealing with heritage consumers in the context of the leisure market, suggested six motivations: pleasure of viewing, education, information, relaxation, entertainment and exercise. It is argued here that these may be applicable to any form of cultural tourism and are not necessarily linked to the heritage presented, which is arguably central to a heritage site. Moscardo [7], while clarifying 
the role of interpretation in the context of the management of heritage sites, emphasized two main motivations: educational and entertainment / social. However, it was again felt that the heritage site was perceived mainly as 'another museum' or 'cultural attraction' rather than 'someone's heritage'. The above theoretical background could be helpful to tourists understanding of a visit, for example, to an art gallery, which some would classify as a heritage attraction [8].

It seems that the two most common reasons to visit a heritage site reported in the literature are education (i.e. the tourists' willingness to learn) and entertainment (i.e. the tourists' desire to be entertained). But other reasons, linked to the attributes of the artefacts presented being related to someone's heritage may also play a part. The present research challenges the current approach, not by denying these two most common reasons, but by adding another, namely the desire of tourists to be exposed to their own heritage and thus to be involved in a personal 'heritage experience'. Research in environmental psychology, which explores the link between the individual and the environment, supports the notion that the meaning attached to a space is closely linked to one's experience $[9,10]$. In heritage tourism an alternative view which challenges the traditional way heritage tourism has been understood, has emerged.

In this literature it is argued that the tourists' perceptions of a site and their activities relative to it are important for our understanding of their behaviour [11, 12]. Based on this viewpoint it is argued that viewing heritage tourism as cultural tourism, as suggested by Nuryanti [13] who approached built heritage sites as 'the heart of cultural tourism', is too simplistic. The 'cultural tourism' label hints at activity motivated by curiosity and educational reasons, and ignores the core of such sites- the heritage itself that is presented. This issue is highlighted by the question raised by Swarbrooke [14]: 'heritage education or entertainment?. It is argued that this question may conceal what lies at the heart of this phenomenon: the heritage presented. The importance of such heritage may also be reflected in the reasons for visiting.

\section{Methodology}

The research employs a qualitative method relying on ethnography and phenomenology documentation supported by an in-depth investigation in the Rungus villages within Kudat vicinity (figure 3). It will be supported by architectural detail studies on the longhouse, interviews, naturalistic observation and visual data collection. Ultimately, the expected outcomes include the understanding of the architectural and cultural aspects of the Rungus longhouse (figure 4) in relation to communal space planning and activities.

However, the lack of secondary data requires the researcher to depend on and source out from primary sources. Since this research is focussing on the Rungus cultural interpretation of traditional philosophy of a communal dwelling in a longhouse design context, it is imperative that the study reviews the Rungus customs and understanding of Rungus longhouse. It is known that any culture in the world has a ritual that is related to practices of spiritual, mental and physical well-being associated with their life styles.

The longhouses chosen are the houses that have the most original form of Rungus longhouse. Pilot study identifies specific longhouses before further work can take place. This process involves the phenomenology method looking at the evolution of the longhouse and what influences warrant changes in the longhouse design. However, for this paper there is only one case study investigated. It is based on the Maranjak longhouse in the District of Kudat, Sabah. This research method also involved some non-structured interview of the owners of the longhouse.

This process ran simultaneously with the visual data collection. These steps focus on the residents and their perception of the detail Rungus longhouse space planning while from the experts the interview will focus on types and customs, rituals and philosophy associated with the Rungus cultural system. This method is also looking into the tribal leaders' knowledge on the Rungus longhouse be it associated with any cultural philosophy or traditional customs. Most important of all is the established connection between the traditions and the well-being of the house and how it stands. 


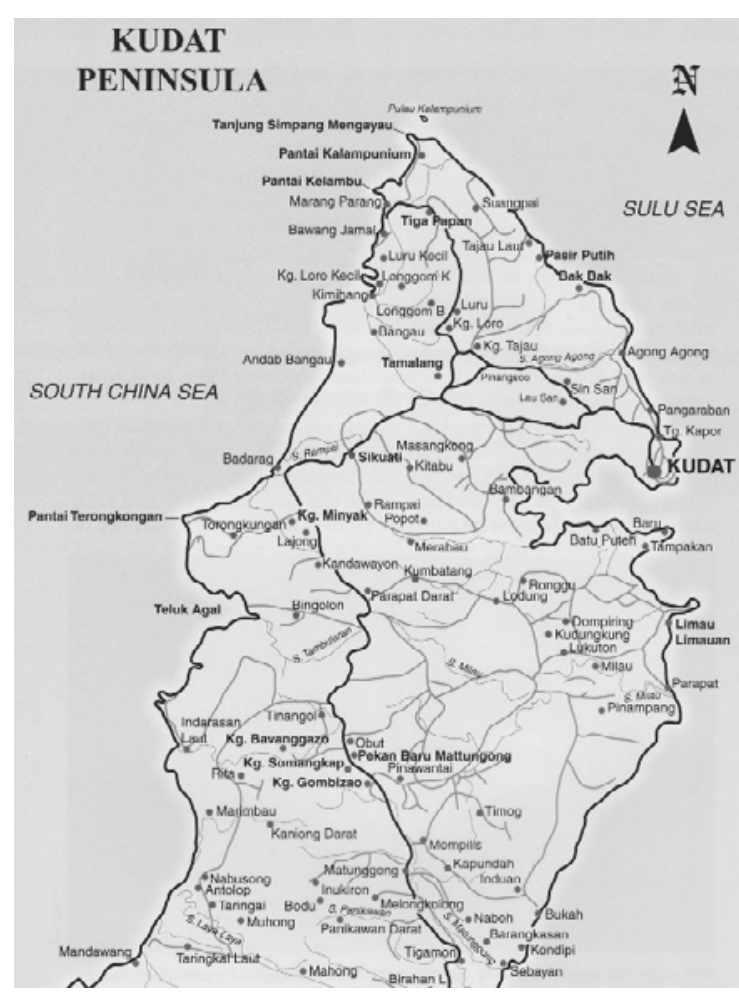

Figure 3. May of Kudat and vicinity Source: Huton, 2003 [15]

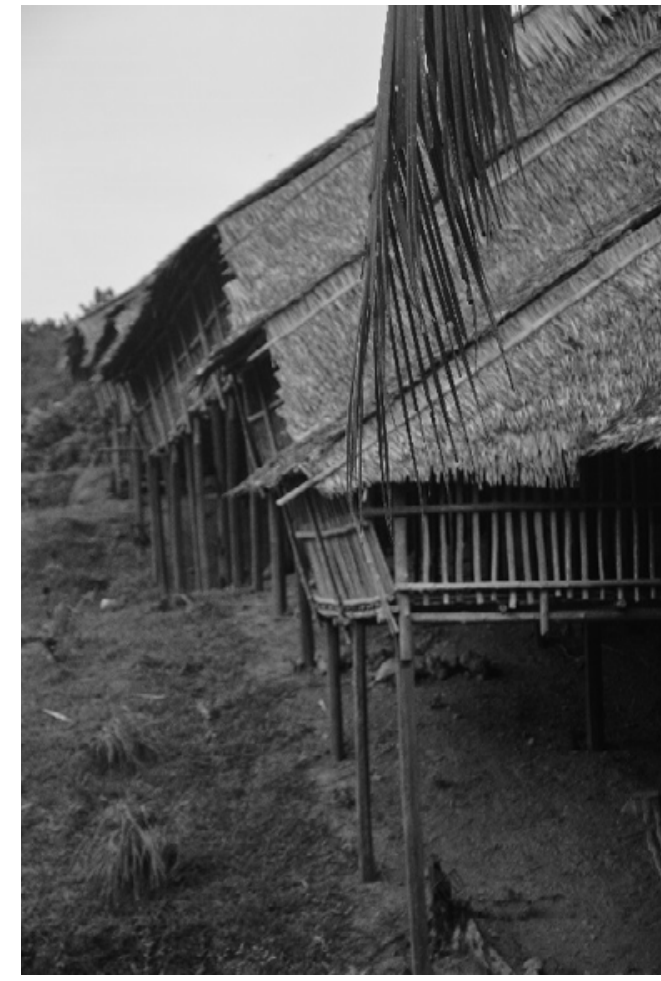

Figure 4. Rungus longhouse

\section{The Rungus Community}

This paper is examining the longhouse of the Rungus people in an area famed for the title 'The Tip of Borneo, along the northern coastal line of Sabah. Though it is uncertain how long the Rungus have been occupying the area, they are considered to be the most traditional tribe in Sabah due to their isolation from the bigger towns for so many years. While many have adapted to modern living rather well, the older generations still clutch to their unique culture and traditions [16]. The Rungus longhouse is singled out for this research for the reason that the Rungus community has lived or are still living in these longhouses. The longhouse embodies a communal house design made up of individual spaces. This interrelationship concept is very valuable to the understanding of the longhouse design. On the other hand, the Rungus longhouse has also been targeted as one of the major tourism attractions in Sabah that contribute to the construction of the improvised version of the Rungus longhouse, a detachment from the authentic form of the structure. Non-Rungus people perceive the Rungus longhouse as a communal dwelling where its occupants share a big house. The villagers are mainly farmers and many of its women are quite renowned in their handicraft making skills. They display a very close knit bond among the people where communal activities demonstrate the involvement of every person in the community [17]. The domestic family's economy is based on (1) the swidden or slash and burn is a system in agriculture where lands are cultivated until its fertility diminishes, then it is abandoned until is restored naturally in the cultivation of rice, maize, cassava, and a variety of vegetables; (2) the raising of pigs, chickens, and frequently water buffalo; (3) the planting and cultivation of a large variety of fruit trees; and (4) the sale of domestic manufactures. The most important of these are clothing of various types that are woven exclusively by women from cotton they have grown, spun into thread, and dyed [18, 19]. These activities are also the governing 
factors in the design direction of the longhouse along with their cultural beliefs and communal activities.

The Rungus in the north of Sabah (Kudat area) are arguably an ethnic group that is rich in traditions and cultural values. They remain remarkably strong in this time of transition, and keep up with an age-old life-style. Their life, as that of most tribes in Borneo, turns around rice: the preparing of the padi filed, or the clearance of a hill plot, the growing of rice and looking after it, and finally the harvest. Large coconut and banana groves enable the Rungus to get cash, but in all, their traditional life-style suits them very much and seems to keep them out of trouble and stress. The Rungus seem to have been the last Dusunic immigrants to Sabah to settle here permanently, long before the arrival of the British. They have up to-date conserved much of their cultural heritage. The Rungus are a subgroup of the Kadazan-Dusun, with a distinctive language and a few dialects, architecture, adat (customs), and outfit. Many people still, especially from the elder generation, dress the way they have attired when they were still unaffected by outside influences, and it is presumed that most of the other tribes of the Kadazan-Dusun community had similar dresses and attires: simple black sarongs for the women, wide black trousers for the men and beaded accessories.

\section{The Rungus Longhouse}

As traditional live styles require traditional living environment, many Rungus live in longhouses, with each family having its own separate quarters off a common hall. At the edge of the communal hall, a well-ventilated platform of split bamboo with outward sloping walls provides a place for socializing and communal work. The Rungus longhouse is quite different from the Murut longhouse. The houses are not perched on high stilts, but are usually only three to five feet above ground (figure 5). The roof is low, and the walls are outward sloped (figure 6).

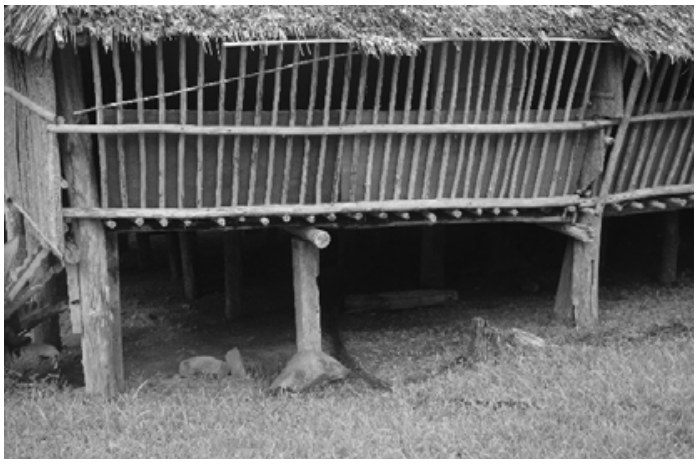

Figure 5. The Rungus longhouse stilts

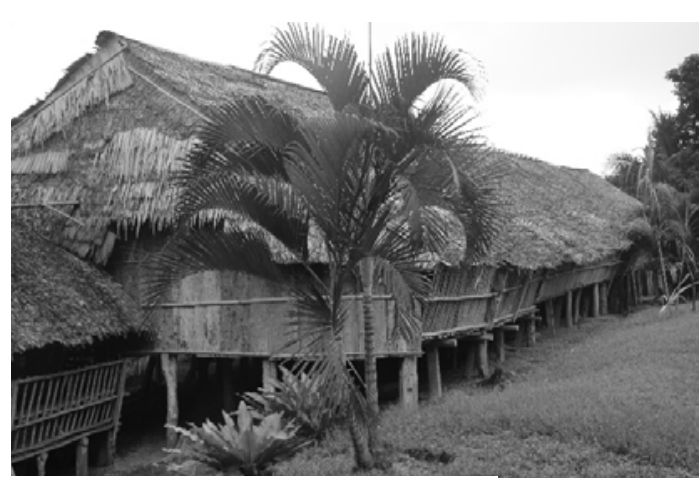

Figure 6. Sloped roof

In olden times, longhouses of over 75 doors are said to have been common. Now, they rarely exceed 10 doors. Usually single story, more modern two-story versions of the longhouse also exist. Single-family houses are sometimes built near the longhouse - these take the same form, but are short. Dogs, chicken and other domesticated animal abound in the clearing where the houses stand, and kids too young to help with the daily chores play in the sand in the clearing. They will quickly announce the arrival of a stranger, and whoever passes will be invited into the house for a rest. During the hot afternoons, a palpable laziness prevails in the houses. People doze on the platform in the gallery or work on some handicraft if they are not at work in the fields, or catch fish and crabs. When everybody comes back from work in the late afternoon, the general area bounces under the many feet. When the house gets alive in the late afternoon, the ladies will take out their work of basketry, string beads or weave sashes on back strap looms. It is not infrequent to see old ladies who have their wrists still encircled in brass coils with white and black shell-bracelets at either end, and wear the traditional home-woven sarong. They also wear antique heirloom beads, and the betel container is an old, finely 
worked Bruneian brass receptacle. Ladies who do wear traditional gear are often very much respected Bobohizans, the shamans of the Rungus. Besides traditional healing with natural herbs the Bobohizans are here to maintain harmony between humans, nature and astral world according to their age-old belief system. This is where customs and traditions play important roles in harmonising the existence of the house. But despite this peace and aspect of eternal sleepiness, the Rungus are far from being disconnected from the modern times. Cash-crops have allowed them already over the last 30 years to earn money, and in some cases wealth. The young people are being educated, some of them having reached university degrees and have entered the Sabah State Government [20].

\section{Case study - The Maranjak Longhouse}

A few selected longhouses in the vicinity of Kudat District are the bases and locations for the pilot study and the field work. The few identified Rungus villages are Kampong Bavanggazo, Kampong Tinangol and Kampong Minyak, Kampong Hobut, Kampong Mompilis, Kampong Garib, Kampong Barangkason, Kampong Onduon, Kampong Mombatu Darat, Kampong Mombatu Laut, Kampong Nangka, Kampong Tinutudan, Kampong Kindangan, Kampong Panudahan Jambu, Kampong Gombizau and Kampong Minikodong in the District of Kudat, Sabah. However, through first observation, many of the houses identified are no longer authentic. They have been through a lot of changes and only a few remaining can be considered authentic. One of the longhouses that still maintains the authenticity of the Rungus architecture is the Maranjak longhouse.

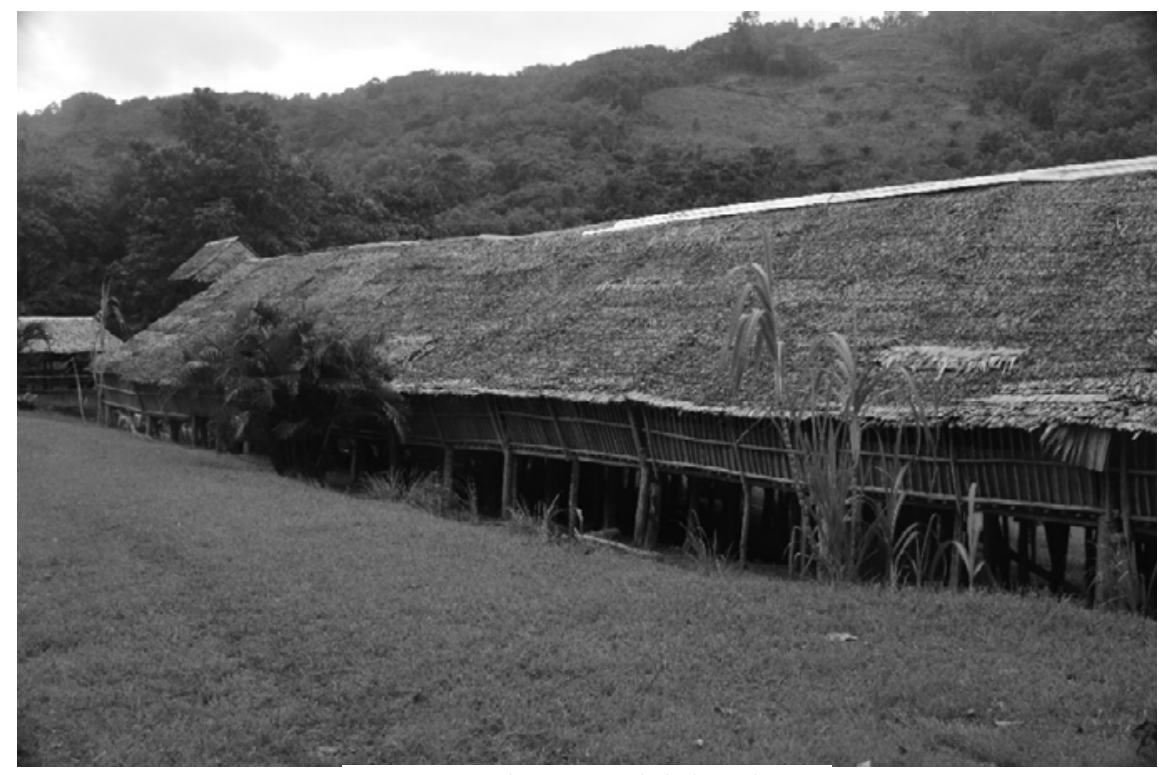

Figure 7. The Maranjak longhouse

The Maranjak longhouse (figure 7) is located in Kampong Bavangazo, Matunggong located about forty kilometres from Kudat. It now serves as a lodge and has a variety of functions and facilities for tourists such as accommodation and recreational activities. Visitors and locals alike will be able to identify a way of life and traditional culture of old Rungus here as it also functions as a museum. Everything in the house is filled with heavy reflections of the local Rungus tribe's cultures and traditions. The buildings in the village are all built with the traditional materials used by people from the past in building their homes such as bamboos, and also palm leaves (for the roof). Although the society has stepped into the modern era, the Rungus tribe is still loyal towards their origins and thus, their homes are mostly built by using these traditional materials as a respect and remembrance of their elder generations. 


\section{The Architectural and Cultural Values of the Longhouse}

The Maranjak longhouse is a very long longhouse in dimension extending to almost 100 metres long. This traditional Rungus longhouse utilises small split timbers lashed with rattan for the frame (figure 8), leaves for the thatched roof (figure 9), bamboo for the floor (figure 10) and tree bark for the compartment walls (figure 11). These materials are sought from the environment requiring rituals and community participation in erecting the house. This longhouse can accommodate more than twenty rooms and houses more than 100 people at one time. It is a house that caters for the communal needs by providing a communal space for meetings and areas for activities and functions (figure 8).

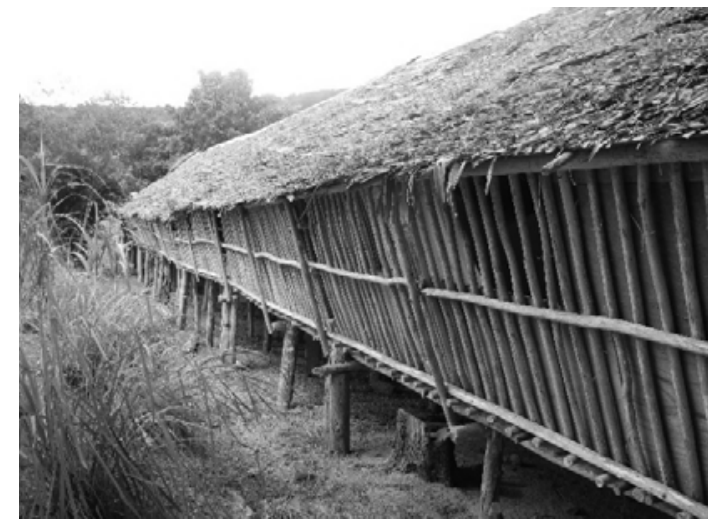

Figure 8. Rattan frames

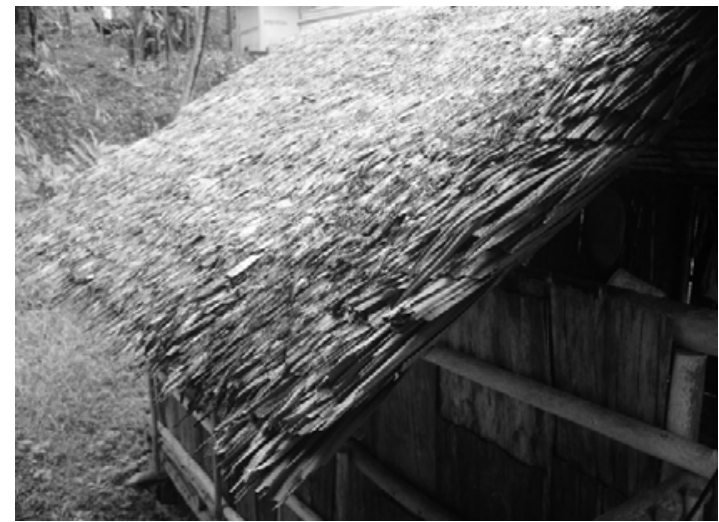

Figure 9. Leaves for thatched roof

The Rungus longhouse is designed in such a way that all daily activities can be done in the shade. Slanted side walls - an element synonymous with the traditional architecture of the Rungus people - allow occupants to sit comfortably without the need for modern or elaborate. This is especially important for the Rungus womenfolk who are renowned for their skills as bead weavers, and have to sit around all day with their legs stretched out to in order to produce their intricate handicrafts. One interesting architectural angle of the Rungus longhouse is that, regardless of the terrain, the occupants of the longhouse will always try to make the building as linear and as parallel as possible - which means an assortment of timber posts of all shapes and sizes propping up the single level floors of the longhouse, some of which may span up to 50-60 metres long. In fact, it was speculated that there once existed a Rungus longhouse in Kudat that had a span of 90 pintu or doors.

Assuming that each door represented a single dwelling unit (approximately 3 metres in width), then this longhouse would have had been 270 metres long. Longhouses were usually built off the ground and along a terraced river bank. The longhouses were built on stilts for a number of reasons including to raise the building above the water should flooding occur, to allow the animals such as pigs, chickens and water buffalo to live underneath, too serve as a refuge or fortress in case of attack and to allow air to circulate throughout the house. One can see that the floor is made from split bamboo for practicality in terms of ventilation and the availability of the material. When one walked on it the floor was soft, spongy and one could feel the breeze come up from underneath. In fact, air circulated freely through the walls, roof and floors. It was cool and a slight breeze could be felt in all rooms. Hence, this architectural and cultural understanding of respecting nature's offerings has established an architectural language of the longhouse [21]. 


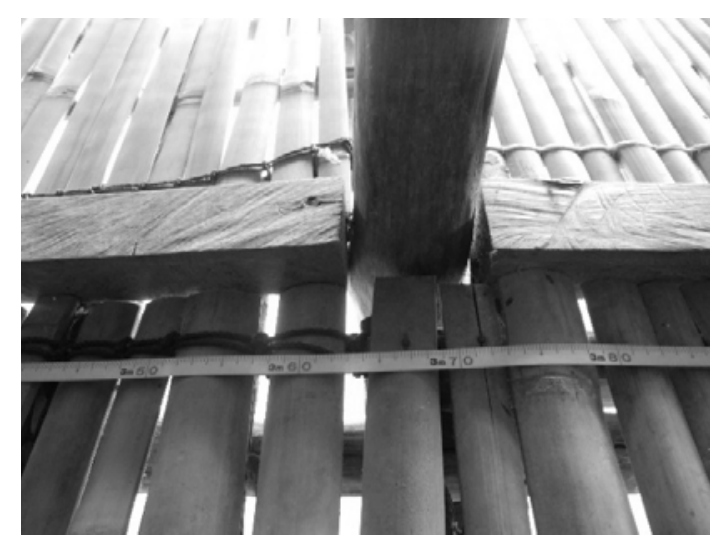

Figure 10. Bamboo floor

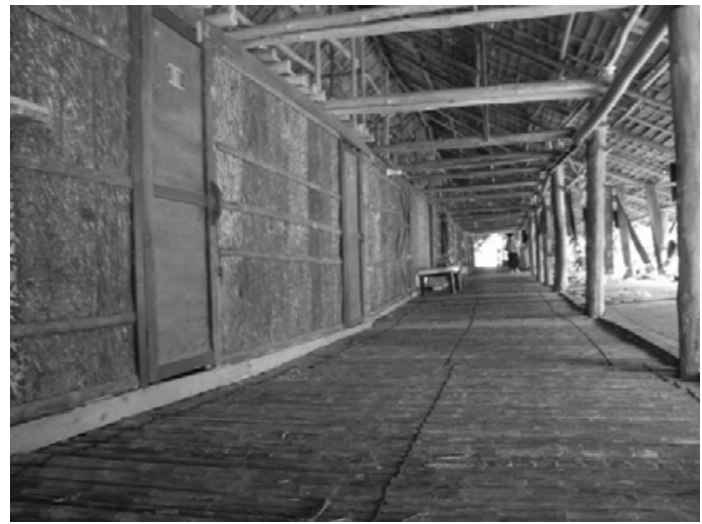

Figure 11. Tree bark compartment walls
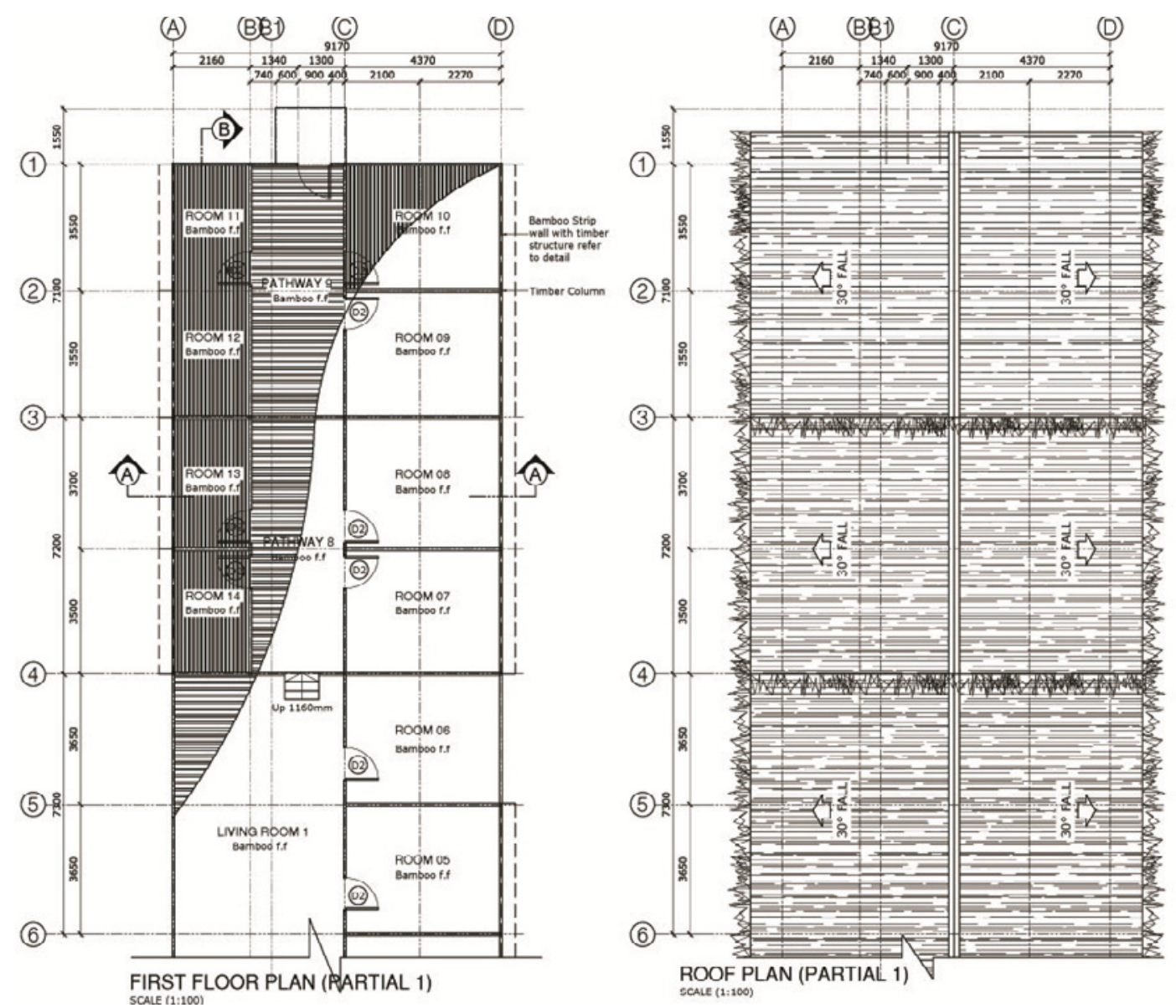

Figure 12. Partial floor plan out of the 100 metres long 


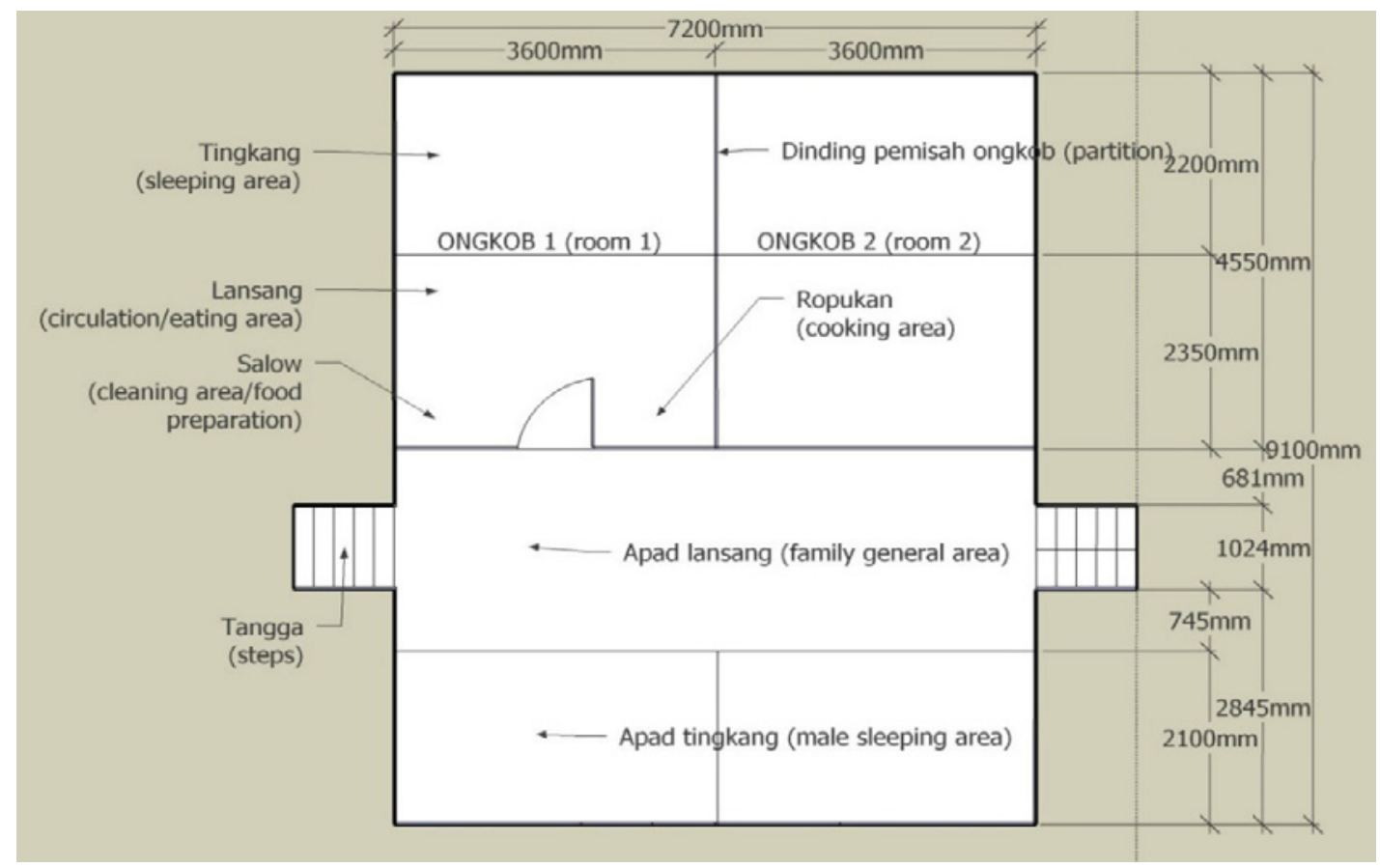

Figure 13. Typical floor plan for ongkob (rooms)

\section{Commodifying Rungus Architecture for heritage tourism}

In commodifying traditional architecture, the natural and protected environments with authentic widespread traditional construction have become one of the fundamental touristic resources. Traditional architecture is a very crucial part of collective cultural heritage. Although it is ample and widespread, only since recent times it has been given its economical value as well as it has been included in tourism [22]. Based on this proposition, the Rungus has the opportunity promote their culture to the wider public specifically using their architecture as a base for all cultural activities. However, Malaysians in general have a vague conception of these longhouses that come complete with clear-cut boundaries of public and private spaces for the domestic families dwelling in these longhouses. Nevertheless, the Rungus longhouse can be targeted as one of the major tourism attractions in Sabah as some villages have embarked into the idea of home stay businesses. In the same line of development, the tourism authorities have appropriated the Rungus longhouse as a communal, primitive and traditional housing pattern existing at the edge of modernization to appeal to potential visitors wanting to revisit 'their past', as supposedly represented by the Rungus community in their 'traditional and communal longhouses' [3]. In the context of change and development, the Rungus longhouse has undergone much transformation and it is seen as another step of highlighting this unique society.

\section{Conclusion}

This paper examines and analyses the longhouse associated with the Rungus culture as the focus of the study in relation to cultural heritage tourism. The research looks into the understanding of the longhouse and the meaning of Rungus cultural beliefs associated with the architecture and context that can be an attraction to tourists. The culture of the Rungus is rich with tangible and intangible cultural components. Among the Rungus there exists a vast inventory of poetry, prayers, songs, hymns related to bobohizan and word pictures of the life that they have led, their relation with the absolute and their 
relations with each other hence the creation of the longhouse to reflect the communal bond. This accumulation of oral literature, winnowed through the ages, is exquisite in its beauty and in its depth of wisdom. It provides a unique portrait of life as lived in a different time and place by individuals who share the human spirit. It encodes the basic cultural themes, values and propositions of this society, and it contains the creative voice of the people. This paper also analyses the Rungus cultural information in relation to communal dwelling of the Rungus longhouse. The research also establishes an architectural language derived from the architectural survey done on the longhouse. The merger between the meaning of the communal dwelling from the traditional Rungus point of definition and the architectural language understanding of the Rungus longhouse becomes a major determinant and contributor in this study. It encompasses issue of an architecture designed for communal activities that is steep in tradition. The finding also includes the understanding of philosophy of Rungus and their interpretation in a contemporary language of architecture. As in the Rungus culture, the longhouse is defined in many aspects of life's activities imprinted with spiritual beliefs and religious teachings. Interpretation from the Rungus cultural point of view on its architecture has shown the meaning of this longhouse in depth and has in a way preserved some cultural and architectural knowledge of the Rungus longhouse despite its extinction. The Rungus culture offers unlimited cultural heritage values that are precious for the people as well as visitors to understand this unique culture.

\section{Acknowledgement}

The authors would like to acknowledge the Universiti Sains Malaysia for funding this research under the Exploratory Research Grant Scheme (ERGS) 203/PPBGN/6730130 and the Sustainable Tourism Research Centre (STRC) with the Long Term Research Grant (LRGS) and the School of Housing, Building and Planning, Universiti Sains Malaysia for this research project.

\section{References}

1. W.E. George. Commodifying Local Culture for Tourism Development: The Case of One Rural Community in Atlantic Canada. University Of Guelph, (2004)

2. Hanafi Hussin - Worldview Dan Amalan: Pengalaman Kadazan Dataran Penampang Sabah. Borneo Research Journal, Volume 1, December 2007

3. P.L. Ong. Rumah Panjang Tradisi Rungus dalam Arus Pembangunan: Perbezaan Pengertian. Akademika 68 , 43-64 (2005)

4. G.N. Appell. Ethnic Groups in the Northeast Region of Indonesian Borneo and Their Social Organizations. Borneo Research Bulletin, 15, 38-45 (1983)

5. A. Massey et. Al. Beware the Animals that Dance: Conservation as an Unintended Outcome of Cultural Practices. Society, Biology and Human Affairs. Durham, (2011)

6. R. Prentice. "Motivations of the heritage consumer in the leisure market: An application of the Manning-Haas demand hierarchy." Leisure Sciences, 15, 273-290 (1993)

7. G. Moscardo. "Mindful visitors: Heritage and tourism." Annals of Tourism Research, 23, 2 , 376397 (1997)

8. G. Moscardo. "Heritage: A key sector of the "new" tourism." Progress in Tourism, Recreation and Hospitality Management, 5 (1993) 309-324 (1993)

9. T. Carling. "Introduction - conceptualizations of human environments." Journal of Environmental Psychology, 18, 69-73 (1998)

10. M.J. Scott and D.V. Canter. "Picture or place? A multiple sorting study of landscape." Journal of Environmental Psychology, 17, 263-281 (1997)

11. Y. Poria, R. Butler and D. Airey. "Revisiting Mieczkowski's conceptualisation of tourism." Tourism Geographies, 5, 1, 26-38 (2003a)

12. Y. Poria, R. Butler and D. Airey. "The core of heritage tourism: Distinguishing heritage tourists from tourists in heritage places.” Annals of Tourism Research, 30 , 1, 238-254 (2003b) 
13. W. Nuryanti. "Heritage and postmodern tourism." Annals of Tourism Research, 23, 2, 249-260 (1996)

14. J. Swarbrooke. "The future of the past: Heritage tourism into the 21st century." In Tourism: The State of the Art, edited by A.V. Seaton. Chichester: John Wiley \& Sons. 222-29 (1994)

15. Hutton, Wendy. Kudat. Natural History Publications: Kota Kinabalu, (2003)

16. Heaven at the Edge of Borneo. Communications \& Publicity Division, Tourism Malaysia. 2 July 2012

17. A. H. B.Pengiran Bagul (ed. Kaye Chon) Community-Based Ecotourism Development and Local Community Participation. One Earth One Family: Travel \& Tourism - Serving a Higher Purpose. 3rd Global Summit on Peace through Tourism - Education Forum. Pattaya, Thailand. October 2-5, p 6, 2005

18. G. N. Appell, G.N. \& Appell L.W.R. Sabah Oral Literature Project: Death among The Rungus of Sabah, Malaysia: The Dissolution Of Personhood And Dispersion Of Multiple Souls And Spiritual Counterparts. Journeys of the Soul: Anthropological Studies of Death, Burial, and Reburial Practices in Borneo, William D. Wilder, Editor. Borneo Research Council Monograph No. 7. Phillips, Maine: Borneo Research Council, Inc., (2003)

19. Anonymous. Penjelasan konsep Magahau berdasarkan keputusan Konvensyen Undang-undang Adat Matunggong. Sabah Daily, (2009)

20. Herman. The Rungus: The Art of Blending Traditional Life-Style into the 20th Century accessed on 27/02/2014 at www.flyingdusun.com, (2000).

21. R.N. Sokial. A Comparison between Traditional Longhouses in Sabah and Sarawak. The Sabah Architectural Heritage accessed on 27/02/2014 at www.sabahwarriors.blogspot.com.

22. Ivana Medica, Pavlo, Ružić, Tomislav Ružić. Architecture as a Tool for Branding in Rural Istrian

Tourism Destination. TURIZAM. 14, 2 (2010) 78-86 (2010) 